\title{
REVIEW OF THE FIFTEENTH INTERNATIONAL CONFERENCE ON METHODS IN DIALECTOLOGY
}

University of Groningen, Netherlands

August 11-15, 2014

Irene SANTOS RAÑA \& Soraya SUÁREZ QUINTAS

Instituto da Lingua Galega - Universidade de Santiago de Compostela irenesantosrana@gmail.com - sorayasuarezquintas@gmail.com

\section{Introduction}

Methods in Dialectology is becoming one of the chief international scientific fora on dialectology. Since 1972 conferences have been held continuously every three years bringing together scholars from all over the world as well as young students embarking on their first work in the area of dialect studies.

Methods in Dialectology started out as a forum for the discussion of methodological issues in dialect research. However, over the years the conference's scope has expanded until, today, while still conserving a title which alludes to the original focus, conferences cover a wide range of issues related to diatopic, diachronic and diaphasic variation.

The fifteenth conference was held in August, 2014 in the Dutch town of Groningen and brought together several dozen papers of a high standard of quality. This year's title, The Future of Dialects, clearly reflects the ultimate goal of combining traditional approaches with recent advances in technology for recompiling data, new tools for analysing it and new interpretations of the concept of dialect in order to gain further insight into linguistic reality, looking ahead towards the future of the field of dialect studies. 
The large number of papers presented in four or five parallel sessions, depending on the day, together with poster presentations, made for a well-organised structure centred around five plenary sessions and eight special sessions which served as a framework for the presentation of specific papers ${ }^{1}$.

\section{Plenary sessions}

Each of the five plenary sessions was led by a key scholar, starting on the first day with Frans Gregersen whose paper, A matter of scale only?, used a Danish data corpus to illustrate different methods of analysis employed in dialect research, and Mark Liberman who presented Dialectology of the future, where he spoke of two key innovations which he claims will bring about important future advances in the field: the spread of universal phonetic analysis and free exchange of dialect data. In Heritage languages as new languages, Naomi Nagy presented a model for intergenerational linguistic comparison between the language of immigrants in the city of Toronto and the language inherited by their offspring. Brigitte Pakendorf reflected on the impact of geographic dispersal as a conditioning factor affecting linguistic fragmentation in Siberia in her paper, Dialectal variation and population genetics in Siberian. The last plenary talk was by Jacob Eisenstein, whose paper Dialect variation in online social media focused on the quantitave and qualitative analysis of texts posted on social media, showing how we also adapt to different contexts when communicating on line.

\section{Special sessions}

In addition to the many papers presented throughout the week there were also eight special sessions, each made up of papers relating to specific issues.

\footnotetext{
${ }^{1}$ See the official website, http://methodsxv.webhosting.rug.nl/, for more information.
} 


\subsection{Syntax across borders}

The objective of this panel organised by Ellen Brandner and Alexandra Lenz was to talk about the effect of extralinguistic borders on syntactic variation in space. The papers all related to a central question: can political, social, cultural and religious borders influence the choice of certain syntactic patterns within a single dialect or between closely related dialects? The discussion focused on Germanic language with particular emphasis on the German and Dutch linguistic situation.

\subsection{Bridging the gap between ELF and receptive multilingualism}

Jelena Golubović was the organiser of this session which offered a forum for researchers on English as a lingua franca who support receptive multilingualism. The papers focused mainly on the concept of intercommunication, and tried to answer the question of how we can communicate effectively while still trying to maintain linguistic diversity.

\subsection{Of vowels and 'systems': New methods for the study of vocalic variation}

Anne Fabricius and Dominic Watt brought together a number of papers looking at the phonetic study of vowels in different varieties of English. The papers illustrated new methods for improving the measurement of vowel formants, suggested new advances in the graphic representation of vowels, offered ways to correct for certain common mistakes in phonetic analysis and presented modern ways of understanding the vocalic space. There were also several perceptive studies of vowel categorization.

3.4 Instrumental articulatory phonetics and dialectological fieldwork. Strange bedfellows?

A group of papers on the instrumental facet of phonetic studies was provided by Etske Ooijevaar, Ben Hermans, Frans Hinskens, Marc van Oostendorp and Patrycja 
Strycharczuk. The presentations explained the advantages of using tools such as Ultrasound Tongue Imaging for articulatory analysis and how this can be applied to studies on variation.

\subsection{Panel studies: Challenges, food for thought and ways forward}

The papers presented by this panel, organised by Suzanne Wagner and Isabelle Buchstaller, were illustrative of the value of longitudinal studies. The session's themes were how to obtain sets of diverse data that can be compared; how the relationship between researchers and informants is created and evolves during research; how to make research data available while respecting informants' privacy; how attitudes to social factors vary between social groups; or, for instance, what statistical tools are best for studies of this kind.

\subsection{Dynamics of dialectal change in French}

The talks in this session, organised by Marie-Hélène Côté, as well as the discussion time following them, focused on geographical variation in French around the world, with special attention to the issues of standardization, dialect levelling and contact between varieties. This was possibly the place where most attention was paid to the subject of the conference, the future of dialects.

\subsection{Frontiers of language variation}

John Nerbonne, Peter Auer, Dirk Geeraerts and Dirk Speelman organised this session which included a variety of studies that look at the implications of fixing the boundaries of isoglosses and identifying the elements that are most likely to exert an influence on the way boundaries between varieties in contact are established. There were other papers about lexical variation where sociolinguistic variables play a decisive role and others focusing on methods of approaching studies of variation. 


\subsection{Open access publishing}

This was a short special session for exchanging ideas and thoughts about making linguistic studies accessible. Speaking in a personal capacity, Martin Haspelmath discussed the Language Science Press initiative which aims to minimise the cost of academic publishing.

There were also two workshops which had a more practical value as training opportunities for researchers. The first was a tutorial on the web application Gabmap, a graphic interface which makes it possible to apply different dialectometrical methods and is useful for drawing maps and providing a graphic, cartographic view of dialect variation. The second workshop, titled Integrating perceptual dialectology and sociolinguistics with geographic information systems, focused on the presentation and use of tools for analysing dialect data such as $\mathrm{R}$ and programmes for representing such data such as GIS, POSTGIS and ArcGIS.

\section{Methods for the study of dialect variation}

Numerous papers in the programme of Methods in Dialectology XV took a close look at the methodology of dialect research. Regarding data collection, two such papers were of particular interest, one of which was read by Víctor Lara Bermejo and the other by a group comprising Dimitris Papazachariou, Maria Giakoumelou, Maria Baltatzani, Evia Kainada and Katerina Nicolaidis. Víctor Lara Bermejo described a data collection method based on the application of dramatic techniques with informants. The second paper discussed the importance of creating an intimate atmosphere during interviews in order to reduce the negative effects of artificial linguistic production and so to improve the quality of results.

Regarding the processing of dialect data, computer applications dominated the discussions, with numerous papers focusing on this aspect. Eveline Wandl-Vogt and Roberto Theron offered interactive visual access to a non-prescriptive dictionary. 
William A. Kretzschmar and Ilka Juuso demonstrated a mobile robot which exemplifies models of linguistic variation by means of a set of rules allowing it to identify geographic locations. Jelena Prokic, Michael Cysouw and Johann-Mattis List presented a tool for automatically segmenting phonetic transcriptions and carrying out multiple alignments of all the words integrated in a database. Marino Fernandes, Michael Routhier and Maya Ravindranath discussed the use of GIS systems to recompile and analyse perceptive dialectology data collected from map-drawing tasks. Sheila Embleton, Dorn Uristescu and Eric S. Wheeler compared three digital systems for processing dialect data: R, Gabmap and General Online Dialect Atlas. Jack Grieve reviewed a wide range of statistical methods for analysing spatial data, while Simon Pickl, in his paper Fuzzy dialect areas and prototype theory - Discovering latent structures in geolinguistic variation using factor analysis, presented a statistical method of data analysis for identifying clearcut dialect areas and fixing the borders of previously unknown spatial structures.

Studies of the methods used in dialectometric analyses also occupied an important place within this area. Here we should mention a study by Gotzon Aurrekoetxea, Karmele Fernández, Jesus Rubio, Gotzon Santander and Iker Usobiaga, who presented Diatech+, an updated and improved version (technically and statistically but also in terms of visual interface) of the Diatech software programme which permits a variety of different dialectometric analyses. In the same vein, Fruzsina Sára Vargha and a team that included Guylaine Brun-Trigaud, Tanguy Solliec and Jean Le Dû demonstrated tools for measuring linguistic distance between different dialects of Turkish and Breton, respectively.

Also using dialectometric tools, Xulio Sousa presented Distance in space: Dialects and standard Galician, in which he analysed the linguistic distance between different Galician dialects and the standard variety. And Simonetta Montemagni and Martijn Wieling likewise used dialectometry to study variation in lexical patterns in Tuscany.

To implement computer tools for processing linguistic variation it is typically necessary to have a data source or a corpus to hand, hence the interest in papers focusing on the process of developing various kinds of language atlas. David Heap went into detail about the history of the Atlas Lingüístico de la Península Ibérica (ALPI); 
Yasuo Kumagai spoke about Linguistic Atlas of Japan (LAP); Robert Sanders and Eric Wheeler gave a presentation about the process of creating an online version of the Chinese dialect atlas, and Yves Scherrer and Sandra Kellerhals examined the development of the Swiss German Dialect Atlas. There were also talks focusing on the development of other types of database, such as those presented by Raïssa Gillier and João Saramago, whose database combines materials from three Portuguese language atlases, ALEPG, ALEMPS and ALEA, and by Yoshiyuki Asahi, which comprises a corpus of oral data collected from the Japanese diaspora in the Americas from the fifties onwards.

Corpora are used as sources of data, yet it is also possible to collect information from texts in the social media in order to find out about the vitality of non-standard varieties in such media. This was touched on in several papers concerned with collecting and analysing data in this kind of context. Jos Swanenberg, in Greetings from Braboneger - Linguistic variation in digital communication, described the Dutch dialect used by a comedian in his tweets and Facebook posts to discover how he constructs a public identity through the use of his own language variety. Twitter also provided a source of data for Maria-Pilar Perea and Antonio Ruiz-Tinoco whose paper How two Catalan dialects coexist in the same areas. An analysis of the use and distribution of some lexical forms in Twitter explores how data collected for Valencian and Balearic varieties of Catalan contrast with the variety considered standard. Finally, Cédric Krummes, Claudia Bucher and Beat Siebenhaar studied the code switching habits and metalinguistic reflections of two users about such switching based on linguistic data in the Swiss SMS - Corpus.

\section{Internal language variation}

Several papers focused on internal variation within language varieties on different levels of analysis: phonetic, lexical or morphosyntactic. 
- Phonetics

On the phonetic level, studies of acoustic aspects of particular varieties of English predominated. Here we may mention, for example, Matthias Hofmann's paper Islanders or Mainlanders? The Canadian Shift in the middle class of urban St. John's, NL and Sandra Clarke and Paul De Decker's Raising from the past: Using digitized sound archives to inform unsolved mysteries in dialectology, which both look at Canadian English.

Here we would also include Maciej Baranowski and Danielle Turton's Linguistic and social constraints on consonantal variation in Manchester English and Daniel Schreier's On context-related variation of hyper-local variants: $/ \mathrm{h} /$ insertion in earlier Tristan da Cunha English, which discuss the social factors involved in the appearance of different consonantal variants in the city of Manchester and the Tristan da Cunha island group, respectively. Similarly, Aaron Dinkin and Robin Dodsworth presented the paper Gradience, allophony, and the Southern shift trigger, which looks at the monophthongization of the diphthong /ay/ in devoiced contexts. In Global demise of a venerable change in progress, Jack Chambers informed of the future extinction of the distinction between $/ \mathrm{hw} /$ and $/ \mathrm{w} /$ in English owing to an accelerating process of fusion of these phonemes.

As for phonetic studies of other languages, Heike Schoormann, Jörg Peters and Wilbert Heeringa presented an acoustic study of the regional distribution of vowels in Saterland Frisian in Acoustic properties and regional variation of Saterland Frisian vowels, and Ichiro Ota, Hitoshi Nikaido and Akira Utsugi gave a detailed picture of tone variation in Kagoshima Japanese in relation to standard Japanese in Tonal variation in Kagoshima Japanese and factors of language change.

Finally, there were also studies of perceptive phonetics such as Cross-regional differences in the perception and production of a sound change in progress by AnneFrance Pinget, René Kager and Hans van de Velde, which examines the relationship between perception and production of $/ v /$ and $/ f /$ in Dutch in the context of an on going change which seems to be leading to the devoicing of labiodental fricatives in word-initial position. The results indicate that the greater the degree of devoicing, the 
less categorical is the perception of it. This seems to fit Eva Bosch Roura's findings in Testing speech perception on the field: Mid vowels in Girona Catalan, which focuses on the methodological implications of perception tests which seem to indicate that in the Girona dialect of Catalan the distance between the phonetic ranges of the mid back vowels [o] and [0] is narrowing.

- Lexicon

Several sessions were devoted to lexical studies. Examples include "Sometimes it gets really intense": Refining the variable context of adjectival intensification by Gerard van Herk and Jennifer Thorburn and The Finnic "itse" as a non-inflecting adverb or an emphatic word by Maria Kok. The former paper examines the phenomenon of intensification and intensified adjectives. The latter analysed the different meanings and uses of the lexical item itse in the Finno-Baltic languages with special attention to its adverbial role.

Then we also had Vilja Oja and Iris Metsmägi's contribution titled Lexical changes in dialect speech, which offers a detailed explanation of the motivations for lexical change, and Study of the internationalization of loanword's phonemes: Based on the results of recorded sound research nationwide by Akemi Yamashita, which examines the causes of pronunciation changes for loanwords in Japanese and discusses regions where the traditional Japanese pronunciation is still maintained.

Regional variation concerning specific lexical items was the focus of papers like Costanza Asnaghi's English influence on written standard Italian: A new concept of regional dialect and the same author's joint paper with Jack Grieve and Tom Ruette, Lexical variation in American English: A web-based dialect survey. The first of these uses a corpus of journalistic material to analyse the influence of English on the standard lexicon of different Italian dialects. The second employs the same search technique to build maps reflecting lexical variation in American English. 
- Morphosyntax

Syntax and morphology received a lot of attention. One example of this, among many others which will be mentioned, was the study The distribution of aggregated syntactic constructions types compared with other linguistic levels... by a group of linguists and geographers who set out to study syntactic features linked to different linguistic variables in order to characterize the Swiss German dialects. Processes of language change in Switzerland were also the subject of Philipp Stöckle and Peter Jeszenszky paper Two-dimensionl variation in Swiss German morphosyntax. These authors together with Robert Weibel presented Exploring global and local patterns of the correlation of geographic distances with morpho-syntactic variation in Swiss German dialects, which establishes the degree of correlation between linguistic and geographical distance in these language varieties.

Examples of studies which analysed syntactic data based on corpora were Ernestina Carrilho and Sandra Pereira's Dialect syntax beyond a corpus: A case study in European Portuguese, and Liina Lindström's Corpus-based dialect syntax: variation and frequency of partitive subjects in Estonian dialects. Another set of papers looked at the frequency of certain elements within syntactic constructions and their possible effect on context: Lexical frequency and syntactic variation: Evidence from U.S. and peninsular Spanish, Variation in openly used person constructions in Border Karelian dialects e How frequent is frequent and why does it matter? Lexical frequency effects on a regular sound change.

Still on the subject of syntax, Benjamin Brosig presented Tense-aspect-evidential differences between Mongolian dialects, which emphasized the distance between Mongolian dialects and their complexity, while Jeroen van Craenenbroeck talked about variation in Holland in a paper titled Measuring correlations in dialect Dutch verb cluster, and Kristel Uiboaed and Maarja-Liisa Pilvik presented Exploring the borders of analycity and syntheticity, which inquires which varieties of Estonian use most analytic constructions.

Then there were papers like Value in the margins: clitic placement in Cypriot Greek by Panayiotis Pappas, and Investigating language landscapes: Variation in verb 
cluster interruption by Lotte Hendriks, which both focus on alternations in certain syntactic patterns of a particular language variety. The first examines clitic placement in Cypriot Greek. The second is an attempt to systematize alternation in the collocation of verbs in standard Dutch.

The most methodologically oriented papers in this group were $A$ study of data compilation methods in Catalan syntax variation by Ares Llop, which looks at procedures for studying the emphatic negative construction, and The relationship between case, word order and referential scales in German dialects by Simon Kasper.

More exclusively concerned with morphology was the paper Adnominal and pronominal agreement with neuter nouns in Belgian Dutch by Karlien Franco and Dirk Geeraerts, which examines lack of agreement between definite articles and demonstratives with neuter nouns in Dutch.

\section{Linguistic variation and extralinguistic factors}

Some of the papers presented have a common theme of studying different sociolinguistic factors which act as factors conditioning variation. Anne-Sophie Ghyselen spoke about the degree of rootedness of tussentaal among two generations of women in Stabilization of Flemish tussentaal: The style-shifting behavior in WestFlanders as a test case, while Wilbert Heeringa and Frans Hiskens, in Visualizing dialect change as such; factoring out the role of the standard language, focused on the influence of standard Dutch on different local dialects of the Netherlands and northern Belgium. Anne-José Villeneuve and Nanna Haug Hilton's paper Structural convergence in minority languages in Europe also discusses the influence of the standard language, in this case along a strip in the French and Dutch domains.

In the same vein, two papers were concerned with dialect levelling. That by Marie-Hélène Côté and Hugo Saint-Amant Lamy, A corpus-based investigation of dialect levelling in Laurentian French, examined the levelling process in the phonetic system of Canadian French; and Ivana Skevin, in Dialect levelling and the change of 
semiotic space, spoke about extralinguistic factors that affect dialect levelling in the lexicon of a variety of Croatian.

Coming now to the study of diastratic factors, in The sociolinguistics of back vowel fronting in Manchester English, Maciej Baranowski looks at the vowels of informants from different social classes to map out correlations between vowel realization and social position. Here we may also mention The future of Welsh dialects? The effects of societal changes on / $r$ / variation in Northern Welsh, which looks at the influence of immigration and immersion in English upon the pronunciation of syllablefinal $/ r /$ in bilingual speakers, and also Ethnic correlates of morphosyntactic variation: Come/ came variation in London, U.K. by Stephen Levey, Sue Fox and Laura Kastronic, and "I sound Irish, like": Implications of immigration for the future of Northern Irish English by Nicholas S. Roberts and Karen Corrigan. Levey et al. look at the relationship between societal factors and variation between come and came in the past tense in non-standard London English, while Roberts and Corrigan study the linguistic competence acquired by the youngest wave of immigrants to Northern Ireland. To round off this section, in The future in a Continental French dialect: polarity versus temporal distance Philip Comeau and Anne-José Villeneuve talk about the relation between use of the inflected future and speakers' socioeconomic status.

Papers with a clearly sociolinguistic interest included several focusing on speakers' metalinguistic reflections and their perceptions of variation. Julia Breuninger and Martin Pfeiffer combined, in Phonological variation and linguistic ideologies in the Upper Rhine area, dialectometric analysis of phonological data with discourse analysis on the level of linguistic ideology, asking what causes the apparent distancing between speakers of the north and south of Alsace. Also connected with borders were Pronominal boundaries between the Südfränkisch and Kleverland dialect areas in Germany and the Netherlands by Frens Bakker and Roeland van Hout, and Linguistic identity in the border of Ourense with Portugal by Soraya Suárez Quintas and Irene Santos Raña.

Attitudes and perceptions were the main focus of Attitudes to varieties of Russian speech among young Russians by Benedikte Fjellanger, and a paper by 
Marjatta Palander and Helka Riionheimo titled Border Karelian recognition test where the authors note that linguistic details are perceived by non-linguists.

Three other talks were more methodological in approach. In Perception: What have we learned? Dennis Preston addressed a number of key questions such as what linguistic elements are taken into account by speakers in their judgments, and what factors influence this. He also had something to say about the future of this area of study, as did the authors of Auditory affective priming: Exploring new methods to measure attitudes to language varieties who evaluated the usefulness of AAP as a technique for analysing informants' positive or negative reactions taking into consideration their reaction time to stimuli. And in Mapping the perception of linguistic form: Dialectometry with perception data, Tyler Kendall and Valerie Fridland provided a sample mapping of data from a phonetic perception experiment using informants from different parts of the United States.

\section{Language change in real time and apparent time}

In the course of the week, a number of papers focused on the relationship between diachrony and diatopy, many of which approached language change in real time and apparent time. These included a paper by the Japanese researcher Chitsuko Fukushima, who compared data from three geolinguistic studies carried out in Japan at different times, and another by Victoria Garnett who combined a set of data about change in real time with another about change in apparent time in order to analyse the role of population movements as an external factor affecting language change. On the same subject, Kenjiro Matsuda analysed this same topic of the problems that arise when comparing linguistic data from different time periods.

A research team from the University of Copenhagen presented a paper titled Intra-speaker variation and change which explores the individual linguistic changes undergone by each speaker during their lifetime, and Fumio Inoue and Takuichiro Onishi contributed with papers which looked from a different angle at the time it takes for a linguistic change to be completed and the characteristics that are favourable to it. 
Still on studies in diachronic variation, Philip Comeau, Ruth King and Carmen LeBlanc read Dialect contact and the sociolinguistic history of Acadian French, a study on linguistic variation through recordings on folk topics and historical sociolinguistic interviews. Lastly, Nynke de Haas presented The Northern subject rule in Northern and Midlands Middle English dialects: be and other verbs, which maps morphological variation in certain verbs depending on adjacent elements in the text corpus.

\section{Dialect variation and school}

A small group of papers focused on the study of linguistic variation among pupils, both in terms of production and perception and also of dialectology itself as a method of work and learning for pupils.

Two similar papers were presented on this subject, one by Laurel MacKenzie, George Bailey and Danielle Turton and another by Gerard van Herk, Paul De Decker and Jennifer Thorburn. Both papers explained the advantages of having pupils collect dialect data and learn to make maps, which is good training while at the same time contributing to the creation and updating of geolinguistic data for a particular language or dialect.

Special attention was paid here to the situation in tussentaal in Flemish schools. Where are we (heading)? A sociolinguistic ethnography of pupils' speech in Flanders reviewed the variants that characterize the tussentaal spoken by a group of secondary students and their reasons for using it. In Between monolingual policy and multilingual classrooms: Mapping the ideological frameworks of Flemish teachers, Steven Delarue considered the difficulties faced by teachers trying to achieve a balance between government-imposed monolingualism and the conservation of the pupils' linguistic variety. Also linked to this topic is the same author's joint paper with Anne-Sophie Ghyselen, Setting the standard: Are teachers the best speakers of standard Dutch?, which looks at the role of teachers as transmitters of standard Dutch in the classroom. Finally, Charlie Farrington's paper Social networks and school demographics in 
longitudinal adolescent data looked at how the school environment and demographic movements influence linguistic variation.

\section{Conclusions}

The diligent yet pleasant atmosphere of the conference culminated in recognition of the work done by the younger researchers. For the first time, the "Chambers Young Scholar Awards" were awarded to the two most highly acknowledged papers, and the "Lisa Lena Opas-Hänninen Awards" were received by the two best poster presentations. The winning oral papers were those of Anne-Sophie Ghyselen for Stabilization of Flemish tussentaal: The style-shifting behavior in WestFlanders as a test case and Simon Pickl for Fuzzy dialect areas and prototype theory discovering latent structures in geolinguistic variation. The prizes for poster presentations went to Stephanie Leser and Lea Schäfer for Imitation as a method of measuring salience and borrowing and Martijn Wieling, the author of Validating and using the PMI-based Levenshtein distance as a measure of foreign accent strength.

The exchange of knowledge that took place during the five days of the conference is certain to provide a good basis for future research which it will be possible to hear about in upcoming editions of Methods. Methods in Dialectology XVI will be held at the National Institute for Japanese Language and Linguistics in Tokyo in August, 2017. 